Article

\title{
The Right of the Contractor To Deviate From The Electronic Sales Contract
}

\author{
Ahmed Shawi ${ }^{1}$ and Raqiya Ali ${ }^{2 *}$ \\ 1 Ministry of Higher Education and Scientific Research; mailto:info.lad@mohesr.gov.iq \\ 2 Ministry of Higher Education and Scientific Research; info.lad@mohesr.gov.iq \\ * Correspondence: ahmad83shawi@gmail.com, mailto:info.lad@mohesr.gov.iq ; Tel.: 009647704658636
}

\begin{abstract}
Recently, during the last century, Communication \& Information revolution caused an essential dynamic in society, especially in legal issues, This dynamic development of information data through this web, it has an essential effect upon the way of civil treatment, which then called "electronic agreements". The industrial and technological development lad to obvious changes in producing processes either for goods or services and then its distributing methods, through using modern media channels, but this factor has a negative side because there is no legal protection for the contractors. This fact leads to the necessity of publishing certain conditions to protect consumers.
\end{abstract}

Keywords: ; Contractor; Electronic Sales; Information revolution and Communication.

\section{Introduction}

Recently, during the last century, Communication \& Information revolution caused an essential dynamic in society especially in legal issues. This dynamic development of information data through this web, it has an essential effect upon the way of civil treatment, which then called "electronic agreements".

The internet consumption contract is one of the most important contracts because the consumer can get rid of the contract; in addition this is one of the most modern risky issues of contracting. With reference to the increasing of these contracts that managed under these novel conditions. Thus, legally we need certain laws under a system that protects the consumer from any kind of damage or risk. This system should be used more than national usage, but should be used globally because it used the web sites to achieve their commercial processes.

Almost, the consumer only knows such data about the goods, or services through internet without having a rest of time to think before signing the contract, or using a sample of this contract. But if the consumer received a sample, so the consumer has the right to sign the contract or not.

This paper discusses the idiom of "electronic agreement" and explains the rights of getting rid of contracts especially in electronic commercial contracts through introducing the idiom of getting rid of till reaching the legal infrastructure.

\section{The research plan:}

It is divided into three parts, first one, talked about the idiom of electronic agreement; the second part talked about the idiom of getting rid of as a right; while the third one will talk about legal infrastructure of getting rid of and its side effects.

The first part is divided into two requests, the first one talked about the definition of electronic contract, while the second one talked about the elements of electronic contract.

Second part is divided into two requests, first one talked about the definition of getting rid of as a right and its justifications, while the second one talked about the range of the right of getting rid of.

The third part is divided also into two requests to talk about the legal nature of the right of getting rid of as in the first one, while the second one talked about its effects. Then, conclude the results and recommendations.

2.1 First Part 


\subsubsection{First request}

Definition of electronic contract:

The electronic contract has many definitions; they are either jurisprudence or legislative, as a jurisprudence definition it is "treatment that includes three types of commercial agreements, introducing internet services, E-learning through sending data to consumers as a logical data l'; other defined it as "positive acceptance agreement through an audio- visual internet", and "every agreement including the description of goods or services between the supplier and the consumers through using the overseas media technology channels to sign the contract [1]." While the American definition is, "that contract which depends on letter exchanging between buyers and sellers according to such statements that prepared before, and managed to establish contract regulationsl'.

While the legal definition of electronic contract is "every agreement has the positive response from one side then the second part took his role". In other civil definitions "agreement took place either as a whole or part of it through many electronic means".

The Arabian definitions were limited such regulations for the electronic contract and define it as "commercial treatments that started from electronic mailing usages,

While European direction no.: (7097) dated 20, May, 1997 regarding the contracts exactly in item no.: (2) defined the electronic contract as "every contract happened between the supplier and consumer in buying goods or services through using many communication means".

Canadian definition was "contract between a merchant and a consumer without visual means either the situation was positive or negative".

While Iraqi legislation defined it as "every agreement has the positive response from one side, then the second part took his role through electronic means". This definition does not differ from the Iraqi civil law of contracting only in case of discussing the electronic means [2].

\subsubsection{Second Request}

Elements of Electronic Contract

Iraqi law did not limit the contract's elements through a specific statement but it solved such treatments such as justifying, shopping site, causes.

In electronic contracts, we need more than the ability and expressing what we need but also we need the legal effect for this positive response.

According to above mentioned statement, this request will talk about the justification as a one element and another one will talk about the shopping site in electronic contract,

First element

Justification in Electronic contract

Consent is the main element of any contract, without it there is no contract; this can be obviously illustrated from the electronic contracts according to its characteristics. Consent depends on positive request then acceptance; here we shall explain the positive request as well as acceptance in electronic contracts.

Firstly: the positive request in electronic contract

In general, positive request refers to a request that direct to a specific person or none specific, but the positive answer should be explicit either orally, written, or through getting such situation without any ambiguity. The positivity can be also defined as a legal expression that announced from one of the contractors to others. And the Egyptian court of cassation defined it as the request that expressed through a man to sign a contract under a legal condition [3].

While the electronic positivity is the same as normal one, but it differs only in the means that used here. So, other defined the electronic positivity as every far distance communication that consisting of all the required elements to empower the receiver to accept the deal. And the most important electronic means that used in positivity through the web are the electronic emails, web pages, chatting rooms, universal shopping.

The condition of positive answering should be assertive, directed to a person or more but limited ones, otherwise it will considered as an invitation of negotiation, moreover, there is a date of being back should be respected from all the deal parts.

Secondly: Acceptance in electronic contract 
Acceptance in general is the positive expression that reflected upon the contract. Electronic acceptance is not far from this context, it is only happened through the electronic means, Thus, there is no different in the main idea or main concept, the differ is only the way of expression such as saying (l agree, Ok.,etc). Here, the main idea because sometimes such expressions give unlimited answers which made confusions, because such askers have a negative malignancy, so the made the statements have an open ends.

While concerning the causes of electronic contract which does not differ from the normal or traditional contract, the Iraqi civil law in its item no.: (132) talked about the contract will be cancelled if the contractor did not took his role legally, or mentioned other none legal items in it, Such after such opinions of Islamic men, the electronic contract should be done as traditional ones [4].

\section{Second element}

Electronic Contract site

Jurists differ in their opinion if the site is an element of a contract or it is an obligated element. Some jurists agree with this opinion and others with another one, Iraqi civil law talked twice about this mater: firstly talking about the contract and the second talking about the site and causes, here site should be available and located or can be located [5].

Site is not different between either the contract is traditional one or electronic to exchange goods, services, soft programs, Thus, electronic contract site or what is called electronic trade is concerning with exchanging the goods and services overseas regarding less the region or nationality, services like law cases, law consultancy, subcontractors, insurance and other services. The electronic contract used the modern techniques in communication which should be real and clear,

Thus, the electronic contract should have a site to be done otherwise the contract will canceled, Because in such cases they use the internet to publish porn photos, trafficking children, misuse of funds, and burglary on credit cards, all these are un legal usages [6].

\subsection{Second part}

The right of recantation

The consumer has the right of recantation to finalize the contract according to the essential law process to protect the consumer from the side effects overseas, Although, we have such exceptions but this right is out of power, thus the consumer will be protected from any suffer, There, we shall talk about the right of recantation in the first request and talking about the region of it in the second request.

2.2.1 First request

Definition of recantation right

The right recantation or what some of jurists called the right of being back is a rescue of the consumer from any bad matters.

First part

Definition of recantation right and its justifications

Firstly: Definition of recantation right

Recantation right of signed contracts overseas is a mean to give a one part a short duration of time to take his time of thinking before the validity of the signature [7]. The recantation right is very important in this context because through overseas contracts, there is no time to think well, thus, recantation rights solve this matter, Moreover, most of legislation in European Union announced that this matter, because it believed that it's a personal right unless the consumer did not sign the contract.

Although we are talking about these legislations but what is important here is that the French legislation, the decree no.: 741 for 2001 especially item no.: 16-121 that said (the consumer can change his deal completely within seven days from the date of good receiving, while services can be considered from the date of signing contract without any fees except the product's returns).

While others, defined it as the (power of some of the contractors to recant the contract) through this system one of contractors can recant friendly without going to court.

There is confusion between the recantation right and the terminated contract, but the first one is a remark for the right that already legislated, while the second one is none and moreover, one part who made this action should take his role in paying the fees or paying the claims. Thus, recantation right with reference to our research is Imean to protect the consumer justification or seller through 
getting his time to think well before signing the overseas contract either the target is good or service.

" Secondly: the justifications of recantation right

No doubt that recantation right is to save the consumer or seller from any deceive, but still the recantation right has its justification to be done, bellow such justifications that justify the recantation:

The absence of visual presence of contractors, in which the seller describe only his needs on website with such main characteristics.

Rapid signing of contract without getting a period of time to deal with other website's contracts, In which some time, the deal gets only few minutes to be done, without negotiations, even the contract is like a menu that distributes to all consumers [8].

From above, the needs for justifications come true and meanwhile, the European court insists on free of charge for any kind of contracts and considered it as a recantation right of the consumer.

Second part:

The duration of recantation right:

Announced the recantation right duration either according to French Consumer Law which mention earlier which ends by seven days, or according to Egyptian Consumer Law no. .' 67 for 2006 which limited it by (14) days only. While for the electronic contracts, the duration of recantation right is longer than traditional ones, because it depends of the concept of electronic contract which needs to be from the date of consumer receiving the good or from the date of signing the contract if it is a service,

We illustrated that the different in the durations according to many laws (Consumer protect Law) should be a lower average of thinking duration of time. Again, some of these laws talked about goods as well as services but other like Egyptian law deals only with goods as in item no.:8 of the above mentioned law.

Such jurists said if the consumer can take the right of recantation during receiving the goods, so, he can do it before having the good or services. According to these laws, the duration of recantation right can be submitted as follows:

If it is good so the duration of recantation right starts from the date of receiving the goods till the seventh day unless there is a holiday, so it can passes to another day which follows.

If it is a service, so the duration of recantation right will be from the date of signing the contract till the seventh day unless there is a holiday, so it can passes to another day which follows.

While the Iraq Consumer law, there is no reference to the duration of recantation right, which we hope to be so in future.

Second request

The region of recantation right

There is no limitation for the recantation for goods only but also for services, and in such cases we cannot made this recantation to save the balance of the contracting process to save the merchant as well. Thus, we have main exception and minor ones which illustrated bellow:

First part:

Recantation right cases:

Firstly: with reference to European consumer law no.: 7 for 1997, exactly in item no.:14 that the recantation right should be as a reason for:

Damaged products or destroyed services.

Products or services did not match the standard, and such European countries can add to this law.

Secondly: being back of, according to French consumer law for 1993 in item (L 16121), in which the recantation right is a right of the consumer himself, it depends on which mentioned above or if the good or service did not tested to the consumer,

Thirdly: being back of, according to Egyptian consumer law no.: 67 for 2006, in which this law distinguish between item no.: 8 and 9 between good and services, as in the following:

1. Contract's Recantation cases of goods according to item no.: 8 of the law:

Any damage in the goods

Products or services did not match the standard 
If products or services did not match the standard that contracted on before.

2. Contract's recantation cases of services according to item no.: 9 of the law:

Any damage in the services.

If services did not match the standard that contracted on before.

Even the law gives the right of recantation of service but such jurists asked about the consurner right of recantation in such case like airlines tickets, tourism flies, hotels, cinema tickets, ...etc, because how could get the money after having the service. We shall see in next part.

Although, the Iraqi consumer protection law no.: (1) for the year 2010 did not referred to overseas contracts, and did not talked frankly about the right of recantation but it put a general item for those who have the right of recantation, through item no.: 6/secondly, which said (the consumer has the right to ask for any claims in front of civil courts if the suppler did not transfer him the goods or services as mentioned in the contract). With reference to this item, we can dressed this matter to electronic contracts.

Second part

The contract exception of recantation right

The recantation right in such laws like Egyptian one did not have any exception, while another one, the Consuming French law of 1993 and European decision of 1997 excepted such cases, that the consumer has no recantation right. Even such items like 3, 6 of the European law talked about the recantation right but in such cases of importing contract.

Here, the research will illustrate the subject through talking only about:

Firstly: goods and services contracts that featured as changeable contracts:

If the price of the good or service is changeable and the suppler cannot control this matter, so the suppler have to pay the amount of money that received from the seller, Here the exception is used.

Secondly: services contract that started before the date of recantation right:

If the seller asked for activating the service before the date of recantation right, here, the suppler should explain that the right of recantation will be finished already.

Thirdly: the good's contract that designed as the seller needs:

This includes such products like food manufacturing, because the seller for specific items, or clothing manufacturing if the seller asked for specific standards, then the exception is used here because the damage will be happened for the suppler.

Fourthly: such thinks that can be returned to buyer if it is rapid depreciate:

This includes these goods that either destroyed or broken like glass, or cannot be used again like flowers, food, And for other cases the seller can limit his especial exceptions either it is selected by law or according to buying contract.

Third part

The legislation Nature of recantation right and the side effects accordingly

If the recantation right is a legislation manner, and it is single consumer ability to recantation right of any contract, so is this alternative choice is a right? And if it is not, so what is the legislation nature of recantation right? Then, if there are any side effects of contract's parties, what to do?

First Request

Legislation nature of recantation right

Recantation right resources are either contractor's agreement or legislation statements, Thus, jurist distinguished between two types of recantation right, the first one is agreement recantation, and legislation recantation. In which, agreement recantation includes the power ability concept, and contract infrastructure for the contractors to be back in agreement, as mentioned in Iraqi civil law (buying conditioned by alternative) $[2,4,5]$.

While, if we are talking about the legislation of the recantation right under certain statement of law, we can find there is a difference in the jurist opinion about its legislation origin because this law will destroyed the contract or damaged it.

Thus, the jurist's opinion about the electronic contract and who has the right of recantation, mentioned as follows: 
Firstly: Comparison between the buying electronic contract in which the seller has the right of recantation, and the buying as an experience.

This opinion submits the seller the right of recantation if the buyer gave him the right of exam this good. Here, the contract will be conditioned, meanwhile, this duration will be considered as a (thinking rest of time, or exam period), then if the seller can get this right, otherwise; he lost this right.

Secondly: Unobligated contract:

This opinion submits the seller the right of recantation if the buyer gave him the right of recantation during the contract duration, because the contract is already mentioned this statement. So, without any exam of the good the seller has the right of recantation.

Thirdly: Recantation right is a middle horizon between the right and the excuse, this level authorized the seller to have more than excuse and less than right, which called (legislation ability).

It is a subside path between the two rights either experience or electronic contract, so it is how to environment the electronic contract not recantation right [9].

Far from these opinions, we realized that they dealt with the contract environment more than recantation right,

While those who are talking about the unobligated contract, it should be such penalties because the seller has this right of recantation while the buyer will lose, and some times, the seller get the right of recantation without any justification.

Accordingly, there is no need to talk about the legislation base of the recantation right that depends on certain legislation statements, because this right becomes as a legislation tool that has a great role with contractor's protection especially those who deal with electronic contracts.

Then, what is mentioned is only a review of some opinions that illustrated the environment of electronic contract not the recantation right.

Second request

The effects of recantation right

According to its main importance in consumer's protection, below will illustrate the effects on both the seller and buyer as well.

First part

The effects of recantation right of the seller

If the seller uses the right of recantation during the recantation duration, so the contract will be as if there is contract as all.

But the recantation right will be conditioned because the good should be retained without any damage, otherwise the seller should either pay the amount of money or exchanged into another one, In addition, the seller will pay any transportation fees if the good has been retained with the selling invoice.

\section{Second part}

The effects of recantation right of the buyer

The buyer should retain all the fees that got from the seller if the second get his right of recantation according to the contract. The buyer should retain all the fees, taxes..,etc. while if the contract is for submitting a service, so the amount should be retain with a balance between what is done or not.

The buyer can submit the service, or exchange it or even retire the service accordingly to the right of recantation that used by the seller. And can get the whole fees with maximum (30 days), otherwise the seller will pay the benefits of this amount according to European law no.: 7 of 1997.

While, in Egyptian law [10] the seller all the time has the right of recantation which faced by resistance because it exaggerates too much to protect the consumer.

\section{Results}

\subsection{Firstly: Results:}


1. The electronic contract is an agreement that signed between two parties through overseas mean, and with reference to its specialty, so it needs many novel rescues for protection more than in normal contracts,

2. The selected legal infrastructure made a huge argument among the jurists, and they tried only to environment the electronic contract with the valid laws.

3. The recantation right is a right for the seller or consumer, in which this right considered as an exception from any legal rights, thus, it could be out of the rule of (the obligated power of the contract).

\subsection{Secondly: Recommendations:}

1. The Iraqi jurist should include the right of recantation to protect the consumer according to two no.: (1) of 2010, as a consumer protection from the buyers or cheaters.

2. The Iraqi jurist should get its action towards the legislation of recantation right like French law and counting the duration of recantation right from the date of receiving the good or submitting the service without any fees, unless there is damage or misused from the consumer.

3. A balance between the consumer and buyer to protect them both, to encourage them in expanding the economic markets not verse.

\section{Conclusion:}

The aim of this research is to research and seek for the legislation rules to protect the consumer if he signed an electronic contract; this research explains a big gap between the legal, technical, economical abilities between the buyer and the seller, Thus, this leads us to find more requirements to protect the seller.

\section{References:}

1. Dr. Jalel Al Saedee, contracted problems through electronic website, Al Senuree Library, Baghdad, without year.

2. Iraqi civil law, 40, 1951.

3. Dr, Taher Shawqi Muhamen, electronic buying contract, electronic trade, Arabian Nahdaa Dar, Cairo, 2007.

4. Dr, Abdul Al Majeed Al Hakeem, Dr. Mohamed T aha Basheer, Dr, Abdul Baqi Al Bakree, the brief of regulation theory in Iraqi civil law, part2, regulation rules, Baghdad, 1980.

5. Dr. Abdul Al Majeed Al Hakeem, the brief of civil law, comparative law library, Baghdad, Part 1, 1977.

6. Dr, Sameeh Al Tuhamee, Contracting through internet (comparative study), legislation books Dar, Egypt, 2008.

7. Electronic signature law and Iraqi electronic agreements, 78, 2012.

8. Dr. Khaled Mamdooh Ebraheem, Sigining the electronic contract (comparative study), University Feker Dar, Al Eskandarya, I St publishing, 2008.

9. Dr. Usama Ahmed Bader, Consumer protection in electronic contracting, comparative study, legislation Dar of books, Egypt, 2008.

10. Jordanian electronic agreements law, 85, 2001. 5- Dubai electronic agreements law, 2, 2002, 6- Egyptian consumer protection, 67, 2006. 